\title{
NOTAS ACERCA DE UN DEBATE EN AMÉRICA DEL SUR SOBRE LA DICOTOMÍA «FEMINISMO: ¿IGUALDAD O DIFERENCIA?»
}

\author{
MARÍA LUISA FEMENÍAS \\ Universidad Nacional de la Plata - Universidad de Buenos Aires
}

Recibido: $27 / 12 / 2009$

Aceptado: 18/04/2010

\section{Resumen}

El trabajo examina los antecedentes del debate igualdad-diferencia en el marco sudamericano y sus antecedentes teóricos en Uruguay y en Argentina a principios del siglo XX. La lectura enriquece las interpretaciones tradicionales excluyentes y trata de mostrar cómo para el caso de las mujeres ambas posiciones son necesarias.

Palabras clave: igualdad, diferencia, derechos, categorías.

\begin{abstract}
This paper aims to expose the equality-difference debate main lines as it was held in South America, mainly in Uruguay and Argentine since the beginning of the XX Century. The suggested reading enlarges traditional interpretations and shows how in women cases are needed both positions.
\end{abstract}

Keywords: equality, difference, rights, categories. 



\section{Esquema de un giro}

Cada época tiene -suele decirse- un tema y solamente uno en qué pensar. Según algunas autoras, como Luce Irigaray, la «diferencia» fue precisamente el tema que debía pensar la filosofía de lo femenino a partir de la década de los setenta y, en algunos medios, eso fue así casi hasta finales del siglo XX. En efecto, junto a la radicalización creciente del proyecto ilustrado, comenzó a emerger, fundamentalmente en Francia pero también en Italia, la voz disonante de quienes anunciaban un nuevo orden feminista.

La pérdida de vigencia académica del neo-kantismo favoreció la instalación de una relectura de Hegel que -en la interpretación de Alexandre Kojève-constituyó un punto clave para la subsiguiente comprensión de la «diferencia» en sus varias interpretaciones. Pongo por caso a Gilles Deleuze quién en su Différence et répétition (1968) -en pleno vendaval del mayo francés- intentó responder a la noción hegeliana de diferencia bajo la fuerte influencia de Martin Heidegger y del estructuralismo de Levi-Strauss. De ese modo, Deleuze abrió el camino a una «diferencia» definida como «originaria», que más adelante Jacques Derrida denominó différance y que se entendió en, al menos, dos sentidos. Por un lado, en relación al verbo «diferir», en tanto «no idéntico». Por otro, implicando «dejar para más adelante», es decir, "posponer». Foucault, en su lección inaugural en el College de France (1970), se sumó a las estrategias de escapar de Hegel -en palabras de Vincent Descombes- planteando la cuestión de si abandonar a Hegel obligaba a volver a Nietzsche o a los transgresores «malditos», como Artaud y Bataille ${ }^{1}$.

Desde otra posición teórica, en 1974, Luce Irigaray denunció que, a pesar de que se había puesto la diferencia en el centro del debate, la «nueva filosofía» olvidaba precisamente la diferencia más radical y fundante: la «diferencia de los sexos». A su juicio -sostuvo- los filósofos mantenían posiciones falogocéntricas; en otras palabras, negaban, ocultaban o no se hacían cargo de la diferencia más radical, la otredad más absoluta: la diferencia sexual,

1. Femenías, M.L.. «Diferencia, identidad y ciudadanía». La manzana de la discordia, vol. 3.2, Universidad del Valle, Cali, junio-diciembre de 2008, pp. 41-50. 
negándose a debatirla ${ }^{2}$. Para Irigaray, ese precisamente es el tema de nuestro tiempo ya que constituye el horizonte de sentido del mundo. En función de ello, Irigaray instrumenta una doble estrategia: por un lado, rechazar la filosofía de la Ilustración y el pensamiento moderno en general, incluido el feminismo de Simone de Beauvoir y, por otro, denunciar el ocultamiento de la más activa de las diferencias: la sexual, que se constituye en principio de inteligibilidad de la cultura.

El marco psicoanalítico de Jacques Lacan, del que proviene, permite a Irigaray darle un giro a la cuestión femenina, rechazando lo que denomina el feminismo de la «igualdad», que caracterizó como constructor de las mujeres en el marco de lo Otro beauvoiriano. Es decir, como segundo sexo o sexo subalterno. Vincula así la descripción fenomenológica del ensayo de Beauvoir con una supuesta «voluntad de otredad» de la pensadora. Para Irigaray, instar a las mujeres a buscar «la igualdad» sería simplemente instarlas a homologarse al modelo del varón como norma. En otras palabras, que las mujeres se constituyan en «sujeto»y asuman su trascendencia es, para Irigaray, «un imposible» porque sujeto y varón son sinónimos ${ }^{3}$.

De modo que Irigaray entendió la «igualdad» no en un sentido formal kantiano sino en términos de un mecanismo material homologante a «ser varón»; lo que es tanto materialmente imposible como productor de no pocas distorsiones conceptuales y fácticas. Sumariamente, para Irigaray, la «igualdad» consiste en la mimetización del varón, al enmascarar la propia especificidad femenina. Por eso, en principio, perseguir la igualdad no sólo es aceptar ser la segunda sino, al mismo tiempo, perseguir una meta imposible que deja intactas las bases fundantes del patriarcado. Más aún, es convertirse en su cómplice. Como es bien sabido, la polarización del feminismo en términos de «igualdad»o «diferencia», como posiciones disyuntivas, excluyentes e irreconciliables se abrió paso, sobre todo en Europa, casi hasta nuestros días, diseñando un campo polémico pleno de aristas y distorsiones ${ }^{4}$.

2. IrigaraY, L.. Speculum. Paris, Les éditions de Minuit, 1974. Versión castellana Espéculo de la otra mujer. Madrid, Akal, 2007.

3. Femenías, M.L.. Sobre Sujeto y Género. Buenos Aires, Catálogos, 2000. Cap. «La irrupción de la diferencia».

4. Me extiendo sobre esto en Sobre Sujeto y Género: lecturas feministas de Beauvoir a Butler. Buenos Aires, Catálogos, 2000. Cap.5. Cf. también mis artículos «Igualdad-diferencia: matizaciones y suturas» en GARCíA, M. C. (comp.), Las nuevas identidades. México, Benemérita Universidad Autónoma de Puebla, 2002, pp. 71-84 y «Los Derroteros de la Diferencia». Revista Maracanan. Dossiê Diferenças e Desigualdades. Universidade do Estado do Rio de Janeiro Año IV-1, 2009, pp. 63-82, en colaboración con M. M. Herrera. 


\section{2. ¿Qué, entre nosotrxs?}

Quiero presentar brevemente dos ejemplos para ilustrar los paradójicos senderos por los que avanzamos las mujeres. Como señala Alicia Puleo para otros contextos, se trata de caminos no exentos de retrocesos si atendemos a ciertas consecuencias sociales que marcan los pulsos de la historia. En las autorizadas palabras de Vico, los corsi e ricorsi de la historia ${ }^{5}$. Sitúo mis ejemplos en Buenos Aires y Montevideo, respectivamente. A comienzos del siglo XX, son ciudades periféricas si la mirada se centra en Europa, aunque su situación cultural y política, en general, comparada con muchos otros países, incluidos los europeos, no lo es.

Argentina se beneficia de la sanción de la Ley 1420 (1884), de Educación Común, Laica y Gratuita, que contribuyó a poner al país entre las vanguardias educativas del mundo. Poco después, se creó la Facultad de Filosofía y Letras de la Universidad de Buenos Aires (1896) y se admitió la primera camada de estudiantes -varones y mujeres- con el objetivo de formar educadores/as con conciencia de pertenencia nacional. Esto último se consideró necesario dado que en poco más de diez años la ciudad había casi triplicado su población, debido a las políticas de inmigración implementadas a partir de $1880^{6}$. En ese marco se formaron las y los estudiantes de entonces ${ }^{7}$. Quiero destacar el papel de Elvira López, quién en 1901 presentó su tesis doctoral titulada «El movimiento feminista $»^{8}$. Apadrinada por el neokantiano Rodolfo Rivarola, abogado y famoso penalista, por entonces profesor de Ética y más tarde Decano de la Facultad de Filosofía, Elvira adopta la posición universalista, distanciándose de otras líneas filosóficas en boga. Desde ese marco, denuncia cómo las mujeres no se ven incluidas en el universal, lo que supone, sin más, una exclusión ilegítima que niega al universal mismo qua tal. En efecto, o bien el

5. A. PULEO. «La filosofía como cuestionamiento de la vida cotidiana» en M.C. SPADARO y M. L. Femenías (comp.), Una visión crítica de la enseñanza de la filosofía. Buenos Aires, Catálogos, 2010, pp. 91-114.

6. Cf. Anales de la Universidad de Buenos Aires, tomo XI-XII, p.10. Sobre la creación de la Facultad de Filosofía y Letras, especialmente, pp. 113-114.

7. Spadaro, M.C.. «Diálogo con Elvira López: La educación de las mujeres, un camino hacia una sociedad más justa». En FEMENías, M.L..Perfiles del Feminismo Iberoamericano. Buenos Aires, Catálogos, 2002, pp. 27-40.

8. E.V. LóPEZ, El movimiento feminista. Tesis presentada para optar por el grado de Doctora en Filosofía y Letras. Buenos Aires, Facultad de Filosofía y Letras-Imprenta Mariano Moreno, 1901, pp. 264. Cf. Sobre este tema me extiendo en «Elvira López». En GuERRA, M.J. y HARDisson, A. (comps.), 20 pensadoras del siglo XX. Oviedo-Tenerife, Ediciones Nóbel y Caja Canarias, 2006, pp. 99-109; También, SpadARO, M.C.. «Elvira López y su tesis sobre el movimiento feminista: la educación de las mujeres». Mora, 8, 2002, Dossier en homenaje a los Cien años de Feminismo en la Argentina, con amplia bibliografía. 
universalismo que proclamaba la Constitución Nacional de 1853 no lo era -y había que denunciarlo-, o bien las mujeres debían ser incluidas por derecho propio de beneficios, derechos y obligaciones en pleno uso de la ciudadanía, de la que al momento estaban excluidas. En efecto, como bien lo recuerda Elvira López, la Constitución proclamaba «Todos los habitantes del suelo de la nación argentina gozan de los siguientes derechos, a saber....» Enunciado el universal «todos», López señala la inclusión forzosa de las mujeres; caso contrario, rige la falacia pars pro toto. Por eso, López insiste en que silenciadas en la historia, la literatura y la filosofía que los varones escriben y enseñan, sólo se transmite la mitad de esa historia, de la literatura y de la filosofía; situación que insta a revertir ${ }^{9}$. Ese es el hilo conductor de su tesis, como se constata en el siguiente pasaje:

No falta quien diga que el feminismo pretende la igualdad de los sexos, lo cual es absurdo si se piensa que igualdad en este caso significa identidad, pero muy justo si se reconoce como expresión de equivalencia. Digamos con Legouvé: «nadie pretende asimilar la mujer al hombre; este sería el medio más seguro de esclavizarla, pues un ser colocado fuera de su natural esfera es necesariamente inferior y por consiguiente está avasallado, en esta diferencia en vez de un signo de inferioridad, hallamos precisamente la razón de elevarla a mejor suerte» ${ }^{10}$.

Destaco, en primer lugar, el uso del término «feminismo»y, de inmediato, el contrapunto entre «igualdad» e «identidad» por un lado y «equivalencia» $\mathrm{y}$ «diferencia», por otro ${ }^{11}$. Se trata de una lectura scotiana avant la lettre, donde la implementación del formalismo kantiano, en el que se mueven sus conceptos, la lleva a defender necesariamente la igualdad y a rechazar ciertas interpretaciones materiales de la misma ${ }^{12}$. López lo precisa: igualdad ni es asimilación ni es identidad u homologación. Igualdad es equivalencia, es decir, sustracción de las mujeres de su situación de avasallamiento. Así, con (falsa) modestia retórica, agrega: «Sólo los varones inadvertidos confundirían ambas acepciones» (el resaltado es mío). Para una sociedad más justa y equitativa no se trata de implementar una igualdad que implique asimilación de las mujeres

9. LÓPEZ, Op.cit. Cap. II.

10. Idem, p. 15-16.

11. Dejo de lado otras aportaciones de E. López. Para otra versión sobre la recepción de la noción de «feminismo», cf. BARRANCOS, D.. «Primera recepción del término «feminismo» en la Argentina» en Femenías, M. L.. «Feminismos en la Argentina» Dossier, en Labrys, 8, julio-diciembre de 2005, Universidade de Brasilia. Sitio: http://www.unb.br/ $\mathrm{ih} / \mathrm{his} / \mathrm{gefem} / \mathrm{labrys} 8 /$ sumarioprincipal.htm

12. Me refiero al clásico artículo de Joan Scott en el que distingue «igualdad» de «identidad» y «diferencia» de «inferioridad». Cf. SCOTT, J.. «Gender a useful category of Historical Analysis» The American Historical Review, 91.5, 1986. 
a los varones -no se busca una forma de homologación- y en consecuencia rechaza entenderla en términos materiales, subrayando la potencia del marco ilustrado al afirmar que las mujeres gozan «por derecho propio» de igualdad formal.

Paso al segundo de los ejemplos: Sobre feminismo del pensador uruguayo Carlos Vaz Ferreyra, quién lo escribió aproximadamente dos décadas más tar$\mathrm{de}^{13}$. Ante las evidentes desigualdades sociales entre varones y mujeres, Vaz Ferreyra distingue tres posiciones: la claramente antifeminista (que considera estrecha, mezquina e hipócrita), un feminismo simplista o «de la igualación» y, por último, el que él mismo sostiene, que denomina «de compensación». ¿En qué consiste el «feminismo de compensación»? Vaz Ferreyra explica que el modelo «de igualación» pone el acento en el sufragio y otros derechos políticos y civiles legales que hay que atender. Sin embargo, considera que es preciso ir más allá y apuntar a la formación misma del carácter femenino. Por eso, a los aspectos legales -que pleno de optimismo cree que las mujeres no tardarán en alcanzar- agrega la necesidad urgente de formar el carácter femenino, no para la sumisión y la obediencia (en referencia a Rousseau) sino para que alcancen voluntad autónoma y autocontrol (Kant). Las mujeres deben dejar de «vivir para otros», abnegadamente, sin vida propia y desarrollar todas las tendencias de su «naturaleza humana». Por eso, Vaz Ferreyra concuerda en que las feministas tienen buenas razones para sospechar de todos los discursos sobre «su» particular naturaleza. Varones y mujeres tienen igual naturaleza -sostiene- pero la experiencia histórica de la desigualdad de derechos ha engendrado desigualdades de carácter entre mujeres y varones. Esa es la diferencia a la que hay que apuntar con la educación: una educación que debe ser compensatoria de milenios de sumisión obligada.

Como apunta Andreoli, Vaz Ferreyra se esfuerza en diferenciar niveles y aspectos del problema porque -a su juicio- exigen soluciones diferentes. Su idea general es que la situación natural de la mujer es de desventaja biológica porque tienen una posición gravosa en cuanto a las cargas de gestación y crianza. No reconocerlo es simplemente «antifeminismo». Por eso, el «buen feminismo»-como el que propone- debe compensarla, librándola de todo

13. Vaz Ferreyra, C.. Sobre Feminismo. Montevideo, Sociedad Amigos del Libro, 1933, asado en la versión taquigráfica de sus conferencias de 1922 sobre los derechos de las mujeres. Reeditado en edición Homenaje de la Cámara de Representantes, Montevideo, 1963, t. IX, por cuya paginación citaré. Cf. Oliver, A.. «El feminismo compensatorio de Carlos Vaz Ferreyra». En Femenías, M. L.. Perfiles del feminismo latinoamericano. Buenos Aires, Catálogos, 2002, pp. 41-50; ANDREOLI, M.. «El feminismo de Vaz Ferreyra» Mora, 11, 2005, pp. 122-135.

Feminismo/s 15, junio 2010, pp. 193-219 
tipo de sumisión para que -qua humanas-alcancen su libertad y la cuota de progreso a la que son acreedoras ${ }^{14}$.

Según Vaz Ferreyra, la situación de la mujer debe analizarse distinguiendo «cuestiones normativas» y «cuestiones explicativas». La confusión entre ambos niveles constituye una de las falacias del feminismo, tal como la identificó en su Lógica Viva (1910) ${ }^{15}$. En otros términos, distinguió claramente entre «lo formal» $\mathrm{y}$ «lo material»; que, en términos actuales, supone implicaciones formales (necesarias) y materiales (contingentes) respectivamente.

En suma, tanto López como Vaz Ferreyra extraen conclusiones afines favorables a las mujeres. Para López, la exclusión de las mujeres viola el enunciado mismo del Preámbulo constitucional, universalista, y promueve leyes ad hoc como justificación, con las consecuencias del caso. Vaz Ferreyra considera la limitación del sufragio, la incapacidad civil, la imposibilidad de acceso a los cargos públicos (entre otros) como «problemas normativos», que involucran indudablemente cuestiones de «ideal», de lo que «debería ser» o de lo que «debería desearse»; y es ahí donde lo normativo requiere de aspectos explicativos o materiales. En palabras de Vaz Ferreira, «Hay así problemas de hecho, que son lógicamente previos, pues su solución o la creencia al respecto, ha de tenerse en cuenta para tratar los normativos» ${ }^{16}$. Es decir, como otros filósofos, Vaz Ferreyra antepone lo material a lo formal extrayendo consecuencias compensatorias para las mujeres. Lejos de las lecturas de la hermenéutica posmoderna y de la filosofía de la sospecha, desde una perspectiva tan moderna como socialista y liberal, ambos pensadores proponen atender «los hechos» y los «ideales» vinculados a zonas no normativas (de «implicación material», cuyo carácter es contingente y no necesario) sin descuidar el marco universalista que -a su juicio- debe regir toda moral. Porque, no tomar en cuenta las diferencias (en términos de cargas biológicas y de cuidado) y pretender simplemente igualar a varones y mujeres es «mal feminismo» o feminismo insuficiente, es "simplificador» ${ }^{17}$. Por eso si la naturaleza es así; luego hay que organizarse en consecuencia y compensatoriamente.

14. Sobre el Femenismo, pp. 44-46, 70-71, 73.

15. Cf. Vaz Ferreyra, C.. Lógica Viva, Ed. Homenaje de la Cámara de Representantes de la República Oriental del Uruguay, T. IV, Montevideo, 1963. Me limito a cuestiones muy generales, para un tratamiento detenido del tema, cf la Parte I de ANDREOLI, M.. El pensamiento social y jurídico de Vaz Ferreyra. Montevideo, Facultad de Derecho, Universidad de la República, 1993.

16. Cf. SF, p. 20. ANDREOLI, pp.128-9 ss.

17. Considera sólo los «hechos» biológicos y no toma en cuenta la redistribución de cargas agregadas y evitables, vinculadas al hogar y al cuidado, como sí lo hace López. 


\section{Comprensiones, incomprensiones y límites}

El apartado anterior constituye un largo excursus que tiene sus razones. En primer término, me sirve como amplio marco de referencia para confesar una incompetencia. En segundo lugar, me permite anudar una suerte de genealogía localizada para contrarrestar la «desmemoria» de nuestras luchas históricas localizadas.

Retomo, primero, mi extrañada incomprensión de un debate. Hace aproximadamente diez años, me situé en la paradoja igualdad-diferencia e intenté ofrecer una respuesta ${ }^{18}$. En esa oportunidad -recupero ahora sólo algunas líneas generales- me propuse examinar la dicotomía igualdad/diferencia, entendiéndola como un dilema, al que denominé Wollstonecraft ${ }^{19}$. En efecto, Mary Wollstonecraft había reconocido la situación paradójica de las mujeres que reclamaban «igualdad» y al mismo tiempo qua mujeres exigían que se les reconociera «su» diferencia; a saber, su capacidad de gestación, que las definía precisamente como mujeres y que al mismo tiempo que las definió, sirvió como motivo para su reclusión en el ámbito doméstico, hasta nuestros días.

Una comprensión patriarcal de la ciudadanía, de los derechos y de la situación general de las mujeres consiste en ver las demandas de «igualdad»y de reconocimiento de «su diferencia» como incompatibles. Basado en ese supuesto, el patriarcado construyó los espacios público y privado como exhaustivos y excluyentes, masculinos y femeninos, respectivamente. En el espacio público rigen la Ley y la igualdad formal, mientras que, en el privado, por el contrario, la costumbre, los usos o normas consuetudinarias. Por eso, huelga subrayar que una de las críticas más consistentes de la teoría política feminista ha sido justamente desarticular esa dicotomía. Los bien conocidos estudios de Carole Pateman y Nancy Frazer así lo muestran. En castellano, los trabajos pioneros de Graciela Hierro o Cèlia Amorós, también.

Un aporte interesante en ese sentido es precisar los conceptos de «Ley»y de «norma». Fundamentalmente en Vigilar y Castigar, Michel Foucault establece entre ambas cinco diferencias relevantes. Sintéticamente:

1) la norma refiere a los actos y conductas de los individuos en términos de comportamientos comparables. En cambio la Ley remite a un corpus de códigos y textos.

18. Cf. «Igualdad y diferencia en democracia: una síntesis posible» Anales de la Cátedra Francisco Suárez, no 33. Universidad de Granada, 1999, pp. 109-132.

19. Cf. mi Sobre Sujeto y Género. Buenos Aires, Catálogos, 2000. Cap. 3. 
2) la norma diferencia a los individuos e indica umbrales (optimum) a alcanzar. La Ley, por su parte, individua (o tipifica) actos desde el punto de vista de los códigos.

3) la norma se mide en términos cuantitativos y se jerarquiza. La Ley distingue entre actos permitidos o prohibidos

4) la norma valora conductas y busca homogeneizar. La Ley busca condenar.

5) la norma distingue dentro y fuera (normal/anormal). La Ley, en cambio, no tiene exterior: absolución o condena ${ }^{20}$.

Esta distinción muestra cómo el espacio doméstico queda atrapado en conductas comparables que, en última instancia, se dicotomizan en «normales»y «anormales», fuertemente controladas por la presión social. La Ley, por su parte, tipifica acciones en términos de absolución/condena. Por ejemplo, una mujer que no es «madre» cae dentro de las anormalidades (no puedo ser condenada, pero sí censurada, criticada, excluida). Ciertos actos, si no están tipificados como delito, no inflingen la Ley; en consecuencia no reciben condena. Tal ha sido históricamente el caso de la denominada «violencia doméstica»o, más propiamente, de la violencia contra las mujeres perpetrada a veces en el espacio doméstico. Precisamente ahí, además de la reforma de las Leyes, se necesita que la sociedad modifique o reforme sus normas, usos, costumbres, sistemas de creencias y, además, sensibilice respecto de los derechos de las mujeres. Es necesario accionar en ambos niveles; hacerlo en uno sólo es claramente insuficiente.

Por eso, si bien ambos órdenes -formal y material-, quedan perfectamente delimitados, por así decirlo, sus competencias no se invalidan mutuamente sino que, por el contrario, se suman. Las leyes igualitarias son necesarias para evitar regresiones de tipo estamental y prebendario. Pero las leyes, a pesar de su fuerza simbólica incuestionable, no imprimen por sí solas ni igualdad ni equidad al tejido social. Son precisos fuertes cambios en las costumbres, los sistemas de creencias, los modos de entablar vínculos y hasta de posicionarse. En palabras de Arendt, lo primero remite a «lo político» y lo segundo a «lo social»; donde el primer caso es de orden legal y apunta los Códigos como el lugar en el que se establecen y tipifican los derechos y los delitos y el segundo, remite al tejido social, vinculándose a los modos en que las conductas de los

20. El interés de Foucault está puesto en el origen de la «prisión» y las políticas de encierro, pero creo que las precisiones que realiza en su distinción entre Ley y Norma son en este caso pertinentes. Cf. también CAstro, E.. El vocabulario de Foucault. Bernal, UNQui, 2004. Vid: «Ley», «Norma», «Soberanía». 
individuos (varones y mujeres) se constituyen en un ethos tal como advierte Judith Butler. Es decir, cómo la costumbre se torna cultura del Derecho.

En la vida cotidiana, ambos órdenes se entrelazan. La Ley exige su cumplimiento y constituye un referente simbólico para los individuos y su socialización. La trama social, con todo, es más compleja; se entreteje con actitudes, gestos, valores estéticos, éticos, económicos, bromas, chistes, massmedia, etc. Son los modos generales de la convivencia. Modificadas las Leyes a los efectos de evitar segregaciones (lo que aproximadamente es el caso en la mayoría de los países occidentales), el desafío lo constituye precisamente modificar la red de creencias discriminatorias que sostienen las conductas de las personas y sus consecuencias performativas. Es decir, apuntar al problema de la ideología patriarcal que rige las prácticas cotidianas en varones y en mujeres. Porque, en todo individuo (varón o mujer) esto involucra, al menos, dos niveles: uno consciente y otro inconsciente. Revisar y cambiar el primero supone individuos de buena voluntad que quieran modificar sus estilos de vida; es decir, sus hábitos. Modificar el segundo implica bucear en los niveles insospechados de sexismo, en el lenguaje mismo con el que construimos las narraciones y nos relacionamos con los otros/as. Ninguna de esas tareas es sencilla y supone órdenes complementarios y no excluyentes del problema.

Sumar ambos órdenes fue el objetivo de Elvira López y Carlos Vaz Ferreyra, estilos en los que el talante histórico de muchas de nosotras está sumergido. Se trata, en buena medida, del marco general de nuestros posicionamientos aunque puedan distinguirse tendencias y acercamientos a uno $u$ otro extremo dicotómico. Quizá, por eso, también me cuesta pensar un extremo sin el otro; más aún, me resulta imposible. Por eso, es necesario, al mismo tiempo, reclamar leyes igualitarias y desmontar mecanismos de exclusión, discriminación e invisibilización, donde la concienciación, la educación y la socialización paritaria deben ser parte de la «agenda feminista». Si la ecuación mujer = madre y varón = proveedor se soldó históricamente, es necesario proseguir su desmontaje. Con ese interés, no veo la dicotomía igualdad-diferencia en términos excluyentes, sino más bien insto a la sutura de ambas posiciones.

Alcanzada la comprensión actual de la «igualdad» (al menos en un Occidente, más o menos difuso) no creo que la «diferencia» reclame volver al mundo del estatus; no al menos en las democracias que conocemos. En suma, «la diferencia»-que incluye muchas diferencias- apunta más bien a explorar los mecanismos no-formales de exclusión, que se entretejen en el lenguaje, las costumbres, las creencias, las psico-socilizaciones de los individuos varones y mujeres. Es fundamental contribuir, por todos los medios a nuestro alcance, a modificar patrones socio-culturales y conductuales discriminatorios en 
mujeres y varones, con miras a minimizar prejuicios y prácticas ancestrales basadas en la idea de la superioridad natural de cualesquiera de los sexos, o a partir de funciones fijadas a priori debido a su sexo.

Explorar los distintos modos de «las diferencias» es tarea del siguiente apartado.

\section{Modos de decir «diferencia»}

En las páginas anteriores propuse un modo de entender la diferencia acorde a nuestra historia feminista; pero no es el único. Trazaré ahora, con gruesos trazos, un mapa conceptual de los perfiles del pensamiento de «la diferencia» en su encuadre europeo, cuyos matices infinitamente desplegados han acabado por enturbiar el debate mismo ${ }^{21}$.

¿Qué decimos cuando decimos «diferencia»? En las últimas décadas, el feminismo se hace cargo de la noción de «diferencia», abandonando el marco general de la modernidad para instalarse en lo que a veces se consideró una forma de «ampliación del campo de la razón». En su comprensión general, la noción de «diferencia» se desplazó desde su lugar tradicional de inferioridad hasta alcanzar un significado no relacional y positivo en sí mismo. Así, constituye un referente propio de las teorías «post» ${ }^{22}$. De modo que un feminismo basado en la «diferencia» como positivamente otra -por decirlo en palabras de Luce Irigaray- rechaza lo que según la «lógica de la identidad» subsumiría a las mujeres en las normas definidas por el varón; malentendido que mucho más sencillamente había advertido Elvira López. Pues bien, en Speculum, Irigaray despliega ese malentendido histórico. El planteamiento de «la diferencia» comienza precisamente ahí donde no puede llegar «la igualdad», en términos de condición necesaria pero no suficiente para el feminismo ${ }^{23}$. $\mathrm{Mi}$ hipótesis general es que el problema de «la diferencia» suscita, primero, la pregunta (implícita) sobre el grado del «no suficiente».

21. CaVAna, M.L.. «Diferencia» en Amorós, C.. Palabras clave sobre mujer. Navarra, EVD, 1995; de Lauretis, T.. Diferencias. Barcelona, horas y Horas, 1999. Cf. también FemeNíAS, M.L. y HERrERA, M.M.. «Los derroteros de la diferencia». En Maracanan. Dossiê Diferenças e Desigualdades, Ano IV.1, Agosto / Dezembro 2008. Universidade do Estado do Rio de Janeiro (UERJ), 2009, pp. 63-82.

22. «Post» en el sentido de postmoderno, postcolonial, postfeminista, etc., que en los últimos años amplían la noción de «diferencia» a las identidades étnica y cultural, entre otras.

23. A pesar de que considero que hay muchos y variados modos de entender tanto la diferencia como la igualdad, por razones de mejor comprensión y simplicidad, mantengo el singular en ambos casos. Con todo, advierto que riesgosamente se ontologizan.

Feminismo/s 15, junio 2010, pp. 193-219 
¿En qué sentido es «no-suficiente» la igualdad formal? ¿Cuáles son los mecanismos para expandir a otros tejidos no formales los indiscutibles logros de «la igualdad»? Un orden político-simbólico no falogocéntrico, femenino, independiente del masculino y positivamente otro per se, tiene una carga voluntarista y una deriva esencialista, que las posiciones de la diferencia no han podido despejar, con consecuencias ontológicas, ético-políticas y sociolingüísticas complejas. No obstante, ese feminismo se ha convertido, desde comienzos de los ochenta y gracias a su fuerza interpelativa, en el motor impulsor de un conjunto de posiciones teóricas nuevas; incluyendo algunos ríspidos debates que son fuente teórico-problemática de novedades feministas.

Dentro de este marco general, el buceo psicoanalítico lacaniano que lleva a cabo Luce Irigaray constituye una referencia ineludible. Esta psicoanalista -con amplia repercusión en nuestro medio- toma como objeto de su examen los preconceptos sexistas de las teorías freudiana, lacaniana y de la filosófica misma, a la luz de contrastaciones que invitan a la búsqueda de categorías no-sexistas. Parte de reconocer que «lo más prohibido a las mujeres ha sido la filosofía [...] que construyó el edificio más acabado de encubrimiento de la verdad originaria elemental». Es decir, de la diferencia sexual, fundante de toda otra diferencia y sobre la cuál se yergue todo pensamiento y práctica políticas. Irigaray instituye a la diferencia sexual como el principio de la inteligibilidad de la cultura y fundante de prácticas, simbolización, producción de sentido y de lenguaje, todos particularmente sexuados y jerarquizados.

Sin adoptar la categoría de «género», la diferencia sexual le permite inaugurar un nuevo camino de desarticulación de los diversos niveles argumentativos que, tanto en los sistemas filosóficos modernos como clásicos, legitiman el orden falogocéntrico. Y lo hace, a partir de los preconceptos del psicoanálisis, con contundente argumentación lógica al mismo tiempo que reivindica la alogicidad de la mujer como un aspecto más de lo positivamente Otra de la Otra beauvoiriana. A su juicio, si el logos es masculino, lo propiamente femenino es pues su alogicidad. Por eso, nacer mujer ni es superfluo ni un atributo secundario. Históricamente, ha connotado subordinación y exclusión. En la actualidad, para Irigaray y sus seguidoras, este «hecho» no se revierte instalando el paradigma igualitarista de la Ilustración; por el contrario, hay que alcanzar las zonas que el formalismo olvida, con el objetivo de romper la «evidencia» patriarcal y generar extrañamiento y sospecha.

Me pregunto, ise mueve Irigaray en el filo de la paradoja, como quiere Braidotti? ¿Se trata de un intento de lectura oximorónica? Ahora bien, la primera dificultad adviene cuando Irigaray radicaliza «la diferencia sexual» hasta considerar que origina un logos otro femenino. Ese lógos originario, que 
el lenguaje patriarcal oscurece (reduce, invisibiliza, niega), tiene que ser rescatado y traído a la superficie como semiosis de «lo femenino». Desde un punto de vista filosófico, cualquier potencial respuesta a este desafío conlleva un conjunto enorme de problemas tanto ontológico-lingüísticos como éticopolíticos. Por mencionar sólo algunos, un primer conjunto se vincula a las siguientes preguntas: ¿Cabe reivindicar la alogicidad para las mujeres? ¿Estamos frente a un dualismo ontológico de los sexos y/o del sustrato biológico? Si es así, la narratividad falogocéntrica, ¿es reemplazable/da (o complementable/da) por otra? ¿Cuál? En todo caso, ¿Hay traducibilidad entre ambos sistemas simbólico-lingüísticos? ¿Cómo? Un segundo conjunto de problemas gira entono a las siguientes preguntas: ¿Por qué mantener un dimorfismo exhaustivo y excluyente y no un trimorfismo o un plurimorfismo sexual alternativo, dado que el «sentimiento oceánico» freudiano, al que remite Irigaray, habilitaría a ello? En todo caso, ¿cómo encarar el problema de la referencia o, acaso, el de la definición? Estas y muchas otras preguntas quedan en pie recogidas, en parte, por sus seguidoras, quienes las multiplican y despliegan constantemente.

Así, en un extremo, la obra de Luisa Muraro, la filóloga y filósofa italiana fundadora de la comunidad Diotima en Verona y del grupo de Mujeres de la Librería de Milán. Muraro acepta el desafío de generar un Orden simbólico de la Madre, en oposición al orden falogocéntrico u orden simbólico del padre -que gira entorno al falo y que rige los modelos psicoanalíticos tanto freudiano como lacaniano ${ }^{24}$. Las citas que transcribo a continuación, tal como las recoge Romina Lerussi, ayudan a ilustrar esta posición y sus límites. Leo: «[...] muchas prefieren reivindicar la igualdad de derechos o secundar el lenguaje masculino, antes que "sacar" lo más propio de sí, el ser mujer» ${ }^{25}$. He puesto énfasis en «el ser mujer» por la ontologización que conlleva, pero ¿conviene ontologizar los rasgos femeninos? Sostengo que no. Además, hacerlo llama la atención ya que las posiciones de filósofos de la diferencia como J. Derrida o M. Foucault, rechazan la metafísica de la sustancia e intentan inscribir en el discurso abierto y cambiante tanto a sujetos como a objetos.

24. Cf. El orden simbólico de la madre. Barcelona, horas y Horas, 1994. Cf. como ejemplos de la polémica recepción de Muraro, Posada KubisSa, L.. Sexo y esencia. Barcelona, horas y Horas, 1998; RivERA GARRETAS, M.M.. El fraude de la igualdad. Buenos Aires, Librería de Mujeres, 2002; AMORós, C.. La gran diferencia y sus pequeñas consecuencias... para las luchas de las mujeres. Madrid, Cátedra, 2005; HERRERA, M.M.. «Faccia a faccia con el feminismo de la diferencia». En Mora, 15, 2010 (en prensa), entre muchos otros.

25. Citado por R. Lerussi «El feminismo de la diferencia sexual italiano. Mapeo y debates pasados con proyección actual.» (en prensa), quien remite a «El fin del patriarcado ( $\mathrm{Ha}$ ocurrido y no por casualidad)», en El Viejo Topo, n 96, pp. 46-59. El resaltado es mío. 
Sin embargo, Muraro e Irigaray caen en formas más o menos explícitas de ontología y esencialismo.

Como advierte Lerussi, sostener como hace Muraro que «existe algo llamado lo femenino como trasgresión del orden simbólico del padre, que actúa desde un lenguaje que le es esencialmente propio, [...] constituye un problema», y añado más que una solución porque la ontologización no es un problema menor para las mujeres. En principio, porque se cae nuevamente en la trampa -recurrentemente denunciada- de qué sea «lo femenino» por fuera del orden patriarcal vigente. Luego, porque fácilmente se galvaniza «lo femenino» en términos epocales pero convirtiéndolo en transhistórico. De la misma manera, sostener que «[...] la igualdad es una respuesta que empequeñece el sentido original de la diferencia sexual y el sentido político del movimiento de mujeres, al que se atribuye como aspiración fundamental la paridad hombremujer $[\ldots] »^{26}$ a mi juicio implica, por decir poco, una inversión de los polos jerárquicos históricamente constituidos (y no disueltos aún) entre mujeres y varones. En casos así se pierde de vista que ni la igualdad ni la paridad niegan otras reivindicaciones, sean formales y/o materiales: sólo se generan ciertos marcos formales comunes que nos sacan simbólicamente del mundo del estatus promoviendo el del Derecho ${ }^{27}$. Tampoco supone quedar atrapadas en las injusticias e inequidades del patriarcado o desconocer las particularidades de uno u otro sexo. Simplemente implica acceder a leyes no segregacionistas y discriminatorias ${ }^{28}$.

En el otro extremo, el segundo conjunto problema desemboca en el «orden» queer elaborado recientemente por Judith Butler. En efecto, negada la fundamentación biológica del dimorfismo sexual, y radicalizada la veta nominalista, varón y mujer se tornan categorías definidas ad hoc según el mandato de la heteronormatividad compulsiva. Butler ahonda lúcidamente en las consecuencias teóricas y prácticas de la ruptura con el binarismo excluyente y el sustrato biologicista, a los que hace deudores de la metafísica de la sustancia. Resignificando la noción de «performatividad» de John Austin, instala sujetos-agentxs en el espesor de la trama discursiva donde la narración de sí

26. LERUSSI, R. idem,

27. Cf. p.e. Sierra, A. \& De la Nuez Ruiz M. del Pino (edts.), Democracia paritaria (aportaciones para un debate). Barcelona-Canarias, Laertes-Instituto Canario de la Mujer, 2007.

28. Sobre este diferencia me extiendo en «Violencia de sexo-género: El espesor de la trama». En Laurenzo P., MAQUedA, M.L.y Rubio, A. (comp.), Género, violencia y derecho. Valencia, Tirant lo Blanch-Alternativa, 2008.

Feminismo/s 15, junio 2010, pp. 193-219 
se configura a partir de una "performance» que se actúa entre las normas y el deseo ${ }^{29}$.

En suma, el abanico de la diferencia es amplio y puede sintonizarse en varios registros. Tras marcar sus puntos extremos, me interesa revisar brevemente una posición que, no obstante inscribirse entre las feministas de «la diferencia», es mucho más moderada y prudente, aunque no por ello menos aguda y fructífera. Me refiero a la obra de la filósofa belga Françoise Collin, directora de Les Cahiers du Griff y especialista en la filosofía de Hannah Arendt. Collin se pregunta cautelosamente si todavía es posible, y bajo qué condiciones, que mujeres y varones piensen un mundo común ${ }^{30}$. Ya la pregunta marca su distancia, por un lado, respecto del dualismo bio-esencialista de Muraro y, por otro, de las consecuencias queer que extrae Butler.

Sintéticamente, Collin defiende tanto el dimorfismo sexual como el nominalismo. Por ende, cree que es posible un orden simbólico común entre varones y mujeres, sobre cuyas prácticas hay que incidir necesariamente. Para ella, «la cuestión de los sexos» se inscribe en un filo ético-político, que implica el desafío de superar el modo en que históricamente se han establecido las relaciones de poder entre varones y mujeres, en tanto organización social dualizada y jerarquizada, que atraviesa todas las clases y las culturas ${ }^{31}$. En sus análisis, subraya cómo la cuestión de los sexos emerge en el pensamiento de muchos filósofos de forma accesoria a algún problema que juzgan «central». Paradigmáticamente, esto es así en la obra de E. Levinas, quién examina al «otro» (mujer) a la luz de la cuestión de la alteridad radical, con la que lo identifica. Además, la pregunta por el sexo siempre está referida al de las mujeres y sólo a ellas ${ }^{32}$.

Tales planteos habituales del problema -sostiene Collin- desconocen la relación misma. Es decir, el entre los sexos. En otras palabras, el vínculo y los modos vinculares que históricamente han conformado a varones y mujeres. Con esto quiere advertir que la diferencia de los sexos suele pensarse por algunos de sus efectos, pero nunca en su misma articulación. Rechazando un punto de mira esencialista, Collin niega también la «bondad natural» de las

29. Butler, J.. El género en disputa. México, UNAM, 2001; Dar cuenta de sí mismo. Buenos Aires, Amorrortu, 2009. Cf. FEMENÍAs, M.L.. Judith Butler: Una introducción a su lectura. Buenos Aires, Catálogos, 2003; Casale, R. y Chiacchio, C.. Máscaras del deseo. Buenos Aires, Catálogos, 2009

30. Collin, F. «Praxis de la Diferencia». En Mora, 1, 1995, p. 2-17.

31. Cf. FEMENíAS-HERRERA, op.cit, $\S \S$ «Una herencia sin testamento».

32. Para un extenso análisis de este problema, cf. PALACiO, M.. La mujer y lo femenino en el pensamiento de Emmanuel Levinas. Córdoba (Argentina), EDUCC, Coleccción Thesys/12, 2008. 
mujeres como simples víctimas del poder masculino. Sin embargo, tampoco acepta la «superación» de la diferencia sexual en términos de «indiferencia sexual»o «indiferenciación». Ante la existencia de la alteridad como tal, sólo en la experiencia del diálogo se puede pensar cada diferencia. Porque «Nadie sabe qué quiere decir una mujer o un varón) sino escuchándolo» ${ }^{33}$. Porque, aunque atravesada por factores de poder, toda diferencia es recíproca ${ }^{34}$.

Para Collin, no es posible cuestionar el carácter social de la construcción de los sexos sino a partir de lo que denomina una «metafísica de la acción», que no se produce ni a partir de un modelo natural, ni en el borramiento de las diferencias biológicas. Las acciones -la práxis- están atravesadas por el deseo y guiadas por el pensamiento en un mundo plural. No se piensa y se actúa a partir de la palabra-situación heredada, sino para transformar y recrear. No hay tabla rasa desde dónde reconstruir la situación de las mujeres; no hay vuelta a «un origen» (no hay paraíso perdido): «Hay que hacer con lo dado» ${ }^{35}$. El primer paso es aceptar la confrontación dialógica y luchar contra la alienación de ese otro que es sustraído por el yo, en su ilusión de identidad consigo mismo. Porque, la lógica de la dominación sustituye el diálogo con el/ la otro/a por el discurso sobre el/la otro/a, convirtiéndolo en un objeto del que se habla al mismo tiempo que se le niega la palabra propia.

Aguda crítica de la analogía marxista y sus derivaciones para la cuestión feminista de los setenta, Collin sostiene que es preciso abandonar los paradigmas monocausales ${ }^{36}$. Si en algún momento de Beauvoir y el movimiento feminista de los setenta confiaron en la revolución socialista para «liberación de la mujer», a poco de andar vieron que esa «revolución» no traía necesariamente la emancipación de las mujeres. Por eso, a partir de 1970, aproximadamente, de Beauvoir adoptó una actitud francamente feminista tomando la lucha de las mujeres como contradicción primaria, y no como una subsección de la lucha de clases, tal como lo había pensado antes, a pesar de que el marxismo siguió marcando el patrón comprensivo del feminismo. Así, las «relaciones sociales de sexo» se calcaron -continúa Collin- de las «relaciones sociales de clase» como fórmula impactante, sin saber con claridad a qué llevaba exactamente

33. Collin, F. Praxis de la diferencia: Liberación y Libertad. Barcelona, Icaria, 2006, p. 37. Cf. también, HeRrera, M. M.. «Collin, entre la práxis de la diferencia, la liberación y la libertad» Mora, 14, 2009, pp. 125-134.

34. Femenías (2007).

35. Collin, F. «Una herencia sin testamento». En VVAA, Feminismos fin de siglo. Una herencia sin testamento. Santiago de Chile, Fempress especial (on line) 1999.

36. Collin, F. "¿No se nace mujer? ¿Se nace mujer? Las ambigüedades de Simone de Beauvoir». En CAGnolati, B.y Femenías, M. L. (comp.), Beauvoir: Las encrucijadas de «el otro sexo». La Plata, Edulp, 2009.

Feminismo/s 15, junio 2010, pp. 193-219 
la analogía. Porque, si la división en clases tiene un fundamento económico, que se resuelve en la revolución que suprimirá todas las clases, ¿ipuede (debe) abolirse la división de los sexos? ¿Acaso -se pregunta- el dimorfismo y sus funciones pueden abolirse como quiere el anclaje queer? Análogamente, ies viable una sociedad sin sexos? ¿Beneficia a las mujeres? ¿Ese es el objetivo feminista?

Para Collin, la cuestión radica en las consecuencias que se siguen para las mujeres bajo un patrón explicativo marxista ${ }^{37}$. Porque, sostiene, todo parece indicar que puede pensarse un feminismo «sin mujeres», un devenir femenino que paradojalmente, nos excluya tal como lo hace la fórmula de G. Vattimo ${ }^{38}$.

Si esa es la lógica común del diseño analógico y si ha llevado al fracaso histórico al objetivo de la sociedad sin clases, ¿no llevará también al fracaso al feminismo? ¿Es aceptable un feminismo sin mujeres? Caso contrario, ¿es un camino adecuado apostar nuevamente al esencialismo de la mano de $\mathrm{L}$. Irigaray o de A. Fouque, con su propuesta de «rehabilitar lo femenino»? Collin responde negativamente ambas preguntas. Pensar la situación de las mujeres y de la diferencia de los sexos exige, primero, abrirse a la pluralidad de causas porque -sostiene Collin- nunca hay «causas únicas» para las injusticias y las inequidades humanas. Hay diferencia de los sexos pero no hay «contradicción principal» que explique exhaustivamente. El movimiento de mujeres falla cuando quiere encontrar una causa única que agote «su» problema. De ahí la necesidad de distanciamiento crítico y antidogmático respecto de todo (con)texto feminista y no-feminista. Se debe afirmar la diversidad hasta el enfrentamiento de posiciones, para que el movimiento de mujeres integre, favorezca y avance desde sus múltiples coyunturas. Es decir, la diferencia sexual y su jerarquización son parámetros primordiales, pero ni son exclusivos ni excluyentes de otros modos de dominación. Como estamos inmersos/ as en una pluralidad de sistemas de dominación a desmontar, el movimiento de mujeres debe reinventarse en la teoría y la práctica constantemente: debe hacer una praxis de la diferencia sexual. En suma, debe ser una praxis política abierta hecha de muchos comienzos, sin un fin predeterminado, sin garantías y sin testamento:

Las feministas de los comienzos transmiten a las mujeres de hoy una herencia importante, pero es 'una herencia sin testamento' en las palabras del poeta René Char. Tal herencia exige, más allá de su conservación, una iniciativa nueva de parte de quienes la reciben ${ }^{39}$.

37. FEMENÍAS-HERRERA, art. cit.

38. Cf. una crítica a Vattimo en BraidotTi, R.. Sujetos nómades. Buenos Aires, Paidós, 2000.

39. Ibidem; cf. también, Collin «Una herencia sin testamento» en VVAA, (1999) on-line. 
Se trata de la

.... puesta en acto de un diferendo en el que el entendimiento (entente) integra el malentendendido. Te oigo (entends) mal implica que al menos hay ya una escucha, y eso es preferible al 'no dices nada' o 'lo que dices es nada', tal como enuncia el amo, oportunamente sordo a todo lo que no es su propio $\mathrm{eco}^{40}$.

Pensar la diferencia entre los sexos da significado al compromiso político y a la determinación de sus condiciones de posibilidad. Sólo puede adquirir representación a partir de la experiencia real -no sólo simbólica- de las relaciones entre varones y mujeres. Por eso, hay que actuar la diferencia; ese es el enlace de lo político con la creación (poiesis) que implica favorecer el advenimiento de lo que todavía no es.

\section{De la voluntad de indistinción a cómo leer las contribuciones.}

Respecto de los múltiples y complejos problemas de violencia contra las mujeres, suele denominarse «voluntad de indistinción» el desinterés histórico que muestran en general los Códigos, sus redactores y ejecutores, respecto de la tipificación de los delitos que tienen como su «objeto» a sujetos-mujeres. Mi pregunta, abierta a debate y a reflexión, es ¿hay voluntad de indistinción en el interior de las dos grandes categorías clasificatorias (igualdad-diferencia) de los feminismos actuales? De una parte, contamos con mapas bastante minuciosos de las corrientes que se inscriben dentro de lo que se ha dado en llamar «la igualdad», y que van desde el liberalismo al marxismo, pasando por un conjunto de matices tan ricos como complejos. Sin embargo, del otro, ¿contamos con el mismo mapa en el interior de la gran categoría del «feminismo de la diferencia»? «Diferencia» denota y connota de muy diversa manera en distintas teorías, aun cuando se la identifique a todas como «de la diferencia». En esta línea, ¿Son equiparables las posiciones de Luisa Muraro, por un lado, y de Françoise Collin, por otro, más allá de su reivindicación «la diferencia»? Creo que no. En principio, porque mientras Muraro sostiene una posición esencialista, voluntarista y, cuanto menos, circunscripta a un núcleo más o menos cerrado de adherentes, Collin, por el contrario, alienta una praxis amplia, pública, no vinculada a la metafísica de la sustancia y antiesencialista. Si bien ambas defienden «la diferencia», hay una brecha entre una y otra comprensión del concepto ${ }^{41}$. Por eso, el constructo «diferencia», además de

40. Ibidem.

41. Aquí, no tomo en cuenta a J. Butler, quien no aceptaría autodefinirse salvo, quizá, como filósofa lesbiana. 
favorecer la ontologización de una amplia multiplicidad de «diferencias» de diverso nivel y orden, reclama varias tareas por hacer.

En principio, utilizo la noción de «constructo» porque cuál sea la «diferencia» relevante en cada caso implica claramente una construcción sociohistórica regida por cuestiones de índole diversa; siendo el poder una de ellas. Otro desafío pendiente es hacer el relevo exhaustivo de las diversas maneras de entender la diferencia y, consecuentemente, de sopesar también sus variadas contribuciones y límites; tarea que no emprenderé ahora.

Sea como fuere, una primera y vieja distinción filosófica permite reconocer posiciones nominalistas y realistas, en el sentido en que lo enmarca Amorós en un artículo ya clásico ${ }^{42}$. Algunas defensoras de la diferencia reconocen a los sexos binarios de manera esencializada o que desemboca claramente en el esencialismo -sea del tipo que fuere. Tal es el caso de Irigaray, Muraro y, en EEUU, de Carol Gilligan, sólo por mencionar algunos nombres. Si la originalidad de Irigaray consistió en sostener que existe un modo de ser otro, propia o esencialmente femenino, cuyas consecuencias en el orden del lenguaje, la ética, la política o la ciencia, están obturados por el discurso patriarcal, el riesgo que pagó fue la ontologización y la dualización metafísica de ambos órdenes, con sus consecuentes problemas teóricos y prácticos. Sus seguidoras, ancladas en ese nudo gordiano, sugirieron de diverso modo que el fundamento onto-biológico de «ser mujer», que sostiene lenguaje, ética, rasgos del carácter y políticas específicas, debía ser explorado. Su punto de partida está ontológicamente marcado y es sustancialista. No obstante, muchas autoras, Carol Gilligan o la misma Irigaray, lo niegan, y marchan por el filo del asunto, sin lograr convencer a sus lectoras más críticas.

Aceptada la diferencia de los sexos, sin embargo, otras autoras, como Collin, la entienden como «un hecho» político del que históricamente se han seguido para las mujeres consecuencias perjudiciales. Esto quiere decir que niegan que haya un «orden del ser» que predetermine a mujeres y a varones. Por el contrario, sostienen un orden del «hacer», de la acción, de la praxis. De ahí la potencia que esa noción cobra en la obra de Collin, quien en un sentido mucho más amplio de «diferencia», favorece el nivel performativo; punto radicalizado en el que se puede ubicar a Judith Butler.

Estas dos bases teórico-filosóficas permiten establecer afinidades, suturas y puentes entre «igualdad»y «diferencia», por fuera de esos mismos conceptos. La exploración puede ser muy fructífera tanto para el realismo ontológico

42. Amorós, C.. «A las vueltas del problema de los universales, Guillerminas, Roscelinas y Abelardas». En Perfiles del feminismo Iberoamericano. Buenos Aires, Catálogos, 2002. 
como el nominalismo e insta a otro tipo de debate que juzgo de más fuste. Sea como fuere, está claro que quienes desde la igualdad sostienen posiciones esencialistas pueden aproximarse más fácilmente al pensamiento esencialista de la diferencia y tender puentes ontológicos. Por el contrario, quienes mantienen posiciones nominalistas, sean de la igualdad o de la diferencia, tienden suturas teóricas que, por mayor afinidad, exploran el plano político, conformador de los espacios «propios» de varones y de mujeres, respectivamente.

Esas posiciones, la mayoría de las veces implícitas, me permiten distinguir dos marcos teóricos que denomino de nivel «macro» $\mathrm{y}$ «micro» respectivamente. Desde una mirada holística o sistemática propongo un plano comprensivo general consistente y coherente con un conjunto relevante de cuestiones filosóficas con consecuencias políticas. Mientras que las lecturas «macro» aceptan o descalifican posiciones teóricas in toto, propongo una lectura de nivel «micro» -en clave de testigo modesto- ${ }^{43}$ a la manera de las micropolíticas de Guattari o las microfísicas de Foucault.

Una lectura «micro» me permite rescatar las ventajas que para el caso de las mujeres tiene no buscar los beneficios in toto de un sistema, sino las «pequeñas ventajas» estratégicas -situadas y localizadas- que cada posición puede aportar. Desde esta interpretación, defiendo las posiciones more nominalista debido a las consecuencias ontológicas que se siguen de todos los tipos de esencialismo, sin mengua de la necesidad de examinar y recuperar aquellos aspectos, nudos, análisis o sugerencias que contribuyan al mejoramiento general de la situación de las mujeres, tanto respecto de lo legal cuanto de lo socio-político en general ${ }^{44}$. Diferencio mi posición del mero sincretismo en tanto no pretendo conciliar concepciones alternas y divergentes, forzando esquemas conceptuales. Por el contrario, rescato para la causa de las mujeres, como de una caja de herramientas, según la célebre frase de Wittgenstein ${ }^{45}$, todas aquellas contribuciones metodológicas, analíticas, teóricas y prácticas que conduzcan a la visibilización de los mecanismos de exclusión e inferiorización de las mujeres y de lo feminizado. Porque será el empleo político de tales contribuciones lo que las defina como herramientas feministas. En principio, servirán para clarificar los diversos planos en juego y sus solidaridades

43. «Testigo modesto es una figura dentro de una red narrativa /.../ que se ocupa de refigurar los sujetos, los objetos y el comercio comunicativo de la tecnociencia <a> un tipo de vínculos diferente»CC. HarawaY, D.. Testigo_Modesto@segundo_Milenio. HombreHembra@_conoce_oncorratón. Barcelona, UOC, 2004, p. 41.

44. Rescato precavidamente el denominado «esencialismo estratégico» que propone el pensamiento postcolonial. Cf. Femenías (2007).

45. Wittgenstein, L.. Investigaciones Filosóficas. México, UNAM-Crítica, 1986, §§ 11.

Feminismo/s 15, junio 2010, pp. 193-219 
patriarcales. En segundo término, favorecerán la modificación de la realidad patriarcal en la que aún estamos inscriptas, desvelando los modos y estilos de su perpetuación estructural y derivaciones. En esto incluyo nuestra conformación socio-psíquica como individuos humanos, nuestros ideales y nuestras concepciones de la sociedad y de la naturaleza -fuertemente permeados por jerarquizaciones y dicotomías patriarcales-, con las consecuencias a las que la de-jerarquización y rearticulación categorial de la comprensión actual e histórica del «mundo» conlleve.

\section{Tengo los nombres, ¿Dónde están las vidas? ${ }^{46}$}

En América Latina, en los noventa comenzaron a expandirse las políticas de localización, que implicaron un modelo de reconocimiento, no ya de «La Diferencia», en términos de diferencia sexual, tal como en los escritos de Irigaray y de las feministas italianas lideradas por Muraro, sino de las múltiples diferencias que atraviesan a las mujeres ${ }^{47}$. Muchas de esas reivindicaciones, aún cuando rechazan el modelo igualitarista ilustrado por entenderlo como parte de la ideología general de las «feministas blancas» y/o del «Primer mundo», resultan, por un lado, exigencias de inclusión efectiva en los marcos universalistas de las leyes vigentes y, por otro, eliminación de los modos encubiertos o explícitos de exclusión y discriminación. A consecuencia de ello, se adoptaron y adaptaron las teorías francesas del discurso y una pluralidad de análisis provenientes del pensamiento postcolonial, el multicultural y de la subalternidad. Si bien atravesados por la variable «género» (que se impuso desde los ochenta), algunas posiciones se deslizaron rápidamente hacia el esencialismo, sobre todo respecto de la noción de «identidad». A grandes rasgos, de la mano de las políticas del reconocimiento y de la adopción de la «identidad», se giró en torno a dos ejes: i) el étnico-cultural y ii) el de sexo-género, entrelazados. Brevemente, en lo que sigue, mostraré cómo se complejiza la «diferencia sexual» con estos atravesamientos.

En primer lugar, el pensamiento postcolonial y los estudios de la subalternidad contribuyeron a recuperar y reconstruir identitariamente las comunidades originarias y $«$ negras $»^{48}$. En general, se apeló a la historia oral, con especial interés en las redes de supervivencia física y simbólica que, en la

46. Cuarto verso del poema «He preguntado por tu nombre» de Jorge Debravo, Antología Mayor. San José de Costa Rica, Costa Rica, 2009, p. 148.

47. Cf. mis «Género y feminismo en América Latina». En Debate Feminista, 20, n 40, 2009, pp. 42-74 y El género de lmulticulturalismo. Bernal, UNQui, 2007.

48. Adopto las comillas para recuperar de modo no racista «negro/a» y «negritud». Cf. Op. Cit (2007). 
mayor parte de los casos, había quedado bajo responsabilidad de las mujeres. Desde ese marco, la intersección etnia-género está produciendo un importante movimiento teórico-práctico-reivindicativo que, en muchos casos, subraya el valor del «mestizaje». La toma de conciencia del mestizaje favorece análisis críticos, cuidadosos y descentrados que invita a las mujeres a una reflexión no-sexista sobre su propia cultura, resignificando conceptos de la teoría feminista. Cuando a los discursos tradicionales de autoctonía se sumó la perspectiva de género, se favoreció el examen de las relaciones de poder intra e inter genéricas en el interior mismo de la variable de identidad étnica. Se puso así de manifiesto la solidaridad de lo que acertadamente Amorós denominó «pactos patriarcales» en términos interclasistas, metaestables y, por añadidura, interétnicos. Al mismo tiempo, se puso de manifiesto la capacidad de las mujeres de modificar y resignificar los diversos estilos del estatus.

Dentro de ese marco, los discursos sobre la fragmentación del universal favorecieron los procesos de concienciación etnia-género y, paradojalmente, los reclamos de inclusión, produciéndose un proceso de autoafirmación étnico-identitaria con conciencia de género, del que muchas mujeres participan anteponiendo a sus tradiciones el reclamo de sus propios derechos. En procesos de revalorización de la identidad étnica, de la mano de la recuperación de la memoria histórica -incluidos la esclavitud y los exterminios-, las mujeres han contribuido a iluminar modos de resistencia (simbólica y performativa) y de adaptación en aras de la sobrevivencia, y de sitios de emergencia de lo novedoso a partir de confluencias tan ricas como variadas.

Incluso, la fragmentación del universal -a los fines del examen crítico de los mecanismos políticos de inclusión/exclusión-implicó algunos aportes fructíferos en la lectura de las diferencias de sexo-género y etnia en América Latina. Por mencionar sólo algunos, la aceptación de la hermenéutica posmoderna de la deconstrucción y la sospecha, la atenta observación de «las diferencias» (en sus muchos aspectos y niveles, incluyendo las de clase), dentro del marco universalista; la no exclusión a priori del/a otro/a y de su mundo simbólico; la conciencia de que «los blancos» somos una etnia más entre tantas otras y ni siquiera la más numerosa, aunque sí la que, en su conjunto, ostenta mayor poder; la recuperación de las «memorias de la crueldad»; la exigencia de la igualdad real y las reformas Constitucionales a las que todo esto obliga a fin de eliminar primero leyes segregacionistas y luego impulsar políticas no discriminatorias. 


\section{A modo de conclusión sin cierre}

Del breve panorama que acabo de trazar sobre mi comprensión de la diferencia, como testigo modesto localizado en América del Sur, voy a extraer unas conclusiones provisorias aunque positivas. Pretendí mostrar un punto de partida más de las extensas luchas de las mujeres hacia una sociedad más equitativa y despejar el horizonte de reivindicaciones que -como bien advierte Ángela Sierra ${ }^{49}$ - muchas veces responde a intereses de parte, que se montan sobre las luchas históricas de las mujeres.

¿Cuál fue el hilo de este recorrido? La misma «igualdad» generó la agenda y sus criterios para este balance, al denunciar cómo históricamente se inferiorizó la «diferencia» que define a las mujeres. Ante los logros de la igualdad, los análisis de Luce Irigaray desplegaron una nueva escena que puede sintetizarse en términos de «la igualdad formal es insuficiente»o, si se quiere, más filosóficamente, la igualdad es «condición necesaria pero no suficiente» para las mujeres en especial y para los grupos discriminados en general. Respecto de lo legal-público-político, la igualdad cumplió buena parte de su cometido (o al menos mucho se avanzó al respecto aunque haya deudas pendientes). Pero los mecanismos patriarcales de la conformación del carácter en la sumisión, la socialización en la inferioridad, el disciplinamiento del deseo y el amor, entre otros, y sobre todo de las teorías que legitiman la reducción de las mujeres a lo íntimo-doméstico-privado, están aún por explorarse y desmontarse.

Por eso, Irigaray se propone escarbar psicoanalíticamente en zonas previas al anclaje del símbolo fálico. Su objetivo fue mostrar cómo las relaciones patriarcales de poder, basadas en la Ley del padre, sesgan la comprensión de Occidente de las mujeres, reduciéndolas a la inferioridad cuando no al vacío de significante ${ }^{50}$. Denunciada la diferencia fundante varón-mujer, sobre uno de cuyos polos (el masculino) Occidente construyó su lenguaje y sus valores negando al otro, sus seguidoras se posicionaron en alguna comprensión de la «diferencia», como cuestión nodal, con derivaciones diversas. El riesgo más inmediato fue la esencialización del «ser mujeres». La reacción fue la fractalización del binarismo sexual y la apelación a un nominalismo radicalizado. Con todo, la polémica mostró tener capacidad revulsiva, tanto respecto del eje igualdad-diferencia como entre las diversas comprensiones de la diferencia y de la igualdad. Metalépticamente, se favoreció nuestra comprensión de cómo,

49. Sierra, A. \& De la Nuez Ruiz M. del Pino (eds.), Democracia paritaria (aportaciones para un debate). Barcelona-Canarias, Laertes-Instituto Canario de la Mujer, 2007.

50. Así lo entendieron los psicoanalistas argentinos más representativos, Ana María Fernández, Mabel Burín, Irene Meler, Juan Carlos Volnovich, entre otros. 
a lo largo de la historia, se inventaron los significados de la inferioridad, se construyeron las exclusiones y se naturalizaron los estereotipos sexuales. En sus derivaciones, la diferencia incluso contribuyó a mostrar cómo se la potenció a los efectos de excluir, negar o exterminar «las/los diferentes» en etnia, en opción sexual, y en cultura. Es verdad -como advierte Nancy Fraser-que las diferencias se fragmentan al infinito, pero sobre una multiplicidad de «diferencias» intersectadas, pivotan las praxis más urgentes, cuyos ropajes simbólicos exigen revisión constante.

Paradójicamente, el debate central igualdad-diferencia contribuyó a expandir y visibilizar la distancia que media entre lo formal y lo material; la Ley y las prácticas; los planteamientos teóricos y las tradiciones ancestrales que bloquean su aplicación; los sistemas legales y los sistemas de creencias. El debate revivió suficiencias, insuficiencias e inconsecuencias sobre «la cuestión femenina», en una época en que la sumatoria de logros formales y materiales, permite concluir, a mi entender, que el feminismo, lejos de debilitarse en el debate, se fortificó aún a riesgo de la trivialización.

\section{Referencias bibliográficas}

Amorós, C.. «A las vueltas del problema de los universales, Guillerminas, Roscelinas y Abelardas». En Perfiles del feminismo Iberoamericano. Buenos Aires, Catálogos, 2002.

AMORós, C.. La gran diferencia y sus pequeñas consecuencias... para las luchas de las mujeres. Madrid, Cátedra, 2005.

ANDREOLI, M.. «El feminismo de Vaz Ferreyra» Mora, 11, 2005, pp. 122-135.

ANDREOLI, M.. El pensamiento social y jurídico de Vaz Ferreyra. Montevideo, Facultad de Derecho, Universidad de la República, 1993.

BARRANCOS, D.. «Primera recepción del término «feminismo» en la Argentina» en FEMENíAS, M. L.. «Feminismos en la Argentina» Dossier, en Labrys, 8, juliodiciembre de 2005, Universidade de Brasilia. Sitio: http://www.unb.br/ih/his/ gefem/labrys8/sumarioprincipal.htm

BraidotTI, R.. Sujetos nómades. Buenos Aires, Paidós, 2000.

ButLer, J.. Dar cuenta de sí mismo. Buenos Aires, Amorrortu, 2009.

BUTLER, J.. El género en disputa. México, UNAM, 2001.

Casale, R. y Chiacchio, C.. Máscaras del deseo. Buenos Aires, Catálogos, 2009.

CASTRO, E.. El vocabulario de Foucault. Bernal, UNQui, 2004.

CAVANA, M.L.. «Diferencia». En Amorós, C.. Palabras clave sobre mujer. Navarra, EVD, 1995.

ColLIN «Una herencia sin testamento» en VVAA, (1999) on-line. 
COLlin, F. « ¿No se nace mujer? ¿Se nace mujer? Las ambigüedades de Simone de Beauvoir». En Cagnolati, B.y Femenías, M. L. (comp.), Beauvoir: Las encrucijadas de «el otro sexo». La Plata, Edulp, 2009.

Collin, F. «Praxis de la Diferencia». En Mora, 1, 1995, p. 2-17.

COLlin, F. «Una herencia sin testamento». En VVAA, Feminismos fin de siglo. Una herencia sin testamento. Santiago de Chile, Fempress especial (on line) 1999.

Collin, F. Praxis de la diferencia: Liberación y Libertad. Barcelona, Icaria, 2006.

De LAURETIS, T.. Diferencias. Barcelona, horas y Horas, 1999.

Debravo, Jorge. Antología Mayor. San José de Costa Rica, Costa Rica, 2009.

FEMENías, M.L., «Elvira López». En Guerra, M.J. y Hardisson, A. (comps.), 20 pensadoras del siglo XX. Oviedo-Tenerife, Ediciones Nóbel y Caja Canarias, 2006, pp. 99-109.

FEMENíAs, M.L.. «Diferencia, identidad y ciudadanía». La manzana de la discordia, vol. 3.2, Universidad del Valle, Cali, junio-diciembre de 2008, pp. 41-50.

FEMENías, M.L.. «Género y feminismo en América Latina». En Debate Feminista, 20, no 40, 2009, pp. 42-74.

FEMENíAs, M.L.. «Igualdad y diferencia en democracia: una síntesis posible» Anales de la Cátedra Francisco Suárez, no 33. Universidad de Granada, 1999, pp. 109-132.

FEMENÍAS, M.L.. «Igualdad-diferencia: matizaciones y suturas» en GARCÍA, M. C. (comp.), Las nuevas identidades. México, Benemérita Universidad Autónoma de Puebla, 2002, pp. 71-84.

FEMENÍAs, M.L.. «Violencia de sexo-género: El espesor de la trama». En LAURENZO P., Maqueda, M.L. y Rubio, A. (comp.), Género, violencia y derecho. Valencia, Tirant lo Blanch-Alternativa, 2008.

FEMENÍAS, M.L.. El género del multiculturalismo. Bernal, UNQui, 2007.

Femenías, M.L.. Judith Butler: Una introducción a su lectura. Buenos Aires, Catálogos, 2003.

Femenías, M.L.. Sobre Sujeto y Género. Buenos Aires, Catálogos, 2000.

Femenías, M.L. y Herrera, M.M.. «Los derroteros de la diferencia». En Maracanan. Dossiê Diferenças e Desigualdades, Ano IV.1, Agosto / Dezembro 2008. Universidade do Estado do Rio de Janeiro (UERJ), 2009, pp. 63-82.

HARAWAY, D.. Testigo_Modesto@segundo_Milenio.HombreHembra@_conoce_oncorratón. Barcelona, UOC, 2004, p. 41.

Herrera, M. M.. «Collin, entre la práxis de la diferencia, la liberación y la libertad» Mora, 14, 2009, pp. 125-134.

Herrera, M.M.. «Faccia a faccia con el feminismo de la diferencia». En Mora, 15, 2010 (en prensa).

IRIGARAY, L.. Speculum. Paris, Les éditions de Minuit, 1974. Versión castellana Espéculo de la otra mujer. Madrid, Akal, 2007. 
LERUSSI, R.. «El feminismo de la diferencia sexual italiano. Mapeo y debates pasados con proyección actual.» (en prensa)

LÓPEZ, E.V.. El movimiento feminista. Tesis presentada para optar por el grado de Doctora en Filosofía y Letras. Buenos Aires, Facultad de Filosofía y LetrasImprenta Mariano Moreno, 1901.

MurARO, L.. El orden simbólico de la madre. Barcelona, horas y Horas, 1994.

Oliver, A.. «El feminismo compensatorio de Carlos Vaz Ferreyra». En FeMENías, M. L.. Perfiles del feminismo latinoamericano. Buenos Aires, Catálogos, 2002, pp. 41-50.

PALACIO, M.. La mujer y lo femenino en el pensamiento de Emmanuel Levinas. Córdoba (Argentina), EDUCC, Coleccción Thesys/12, 2008.

Posada Kubissa, L.. Sexo y esencia. Barcelona, horas y Horas, 1998.

PULEO, A.. «La filosofía como cuestionamiento de la vida cotidiana». En SPADARO, M.C.y FEMEnías, M. L. (comp.), Una visión crítica de la enseñanza de la filosofía. Buenos Aires, Catálogos, 2010, pp. 91-114.

Rivera Garretas, M.M.. El fraude de la igualdad. Buenos Aires, Librería de Mujeres, 2002.

ScotT, J.. «Gender a useful category of Historical Analysis» The American Historical Review, 91.5, 1986.

Sierra, A. \& De la Nuez Ruiz M. del Pino (eds.), Democracia paritaria (aportaciones para un debate). Barcelona-Canarias, Laertes-Instituto Canario de la Mujer, 2007.

Spadaro, M.C.. «Diálogo con Elvira López: La educación de las mujeres, un camino hacia una sociedad más justa». En Femenías, M.L.. Perfiles del Feminismo Iberoamericano. Buenos Aires, Catálogos, 2002, pp. 27-40.

Spadaro, M.C.. «Elvira López y su tesis sobre el movimiento feminista: la educación de las mujeres». Mora, 8, 2002.

Vaz Ferreyra, C.. Lógica Viva, Ed. Homenaje de la Cámara de Representantes de la República Oriental del Uruguay, T. IV, Montevideo, 1963.

Vaz Ferreyra, C.. Sobre Feminismo. Montevideo, Sociedad Amigos del Libro, 1933.

Wittgenstein, L.. Investigaciones Filosóficas. México, UNAM-Crítica, 1986, §§ 11. 